\title{
A importância do papel da enfermagem na orientação ao aleitamento materno
}

\author{
Agosto é o mês mundial do aleitamento materno e o/a enfermeiro/a exerce papel fundamental \\ no acompanhamento e orientação das futuras mães
}

Por Daiane Brito

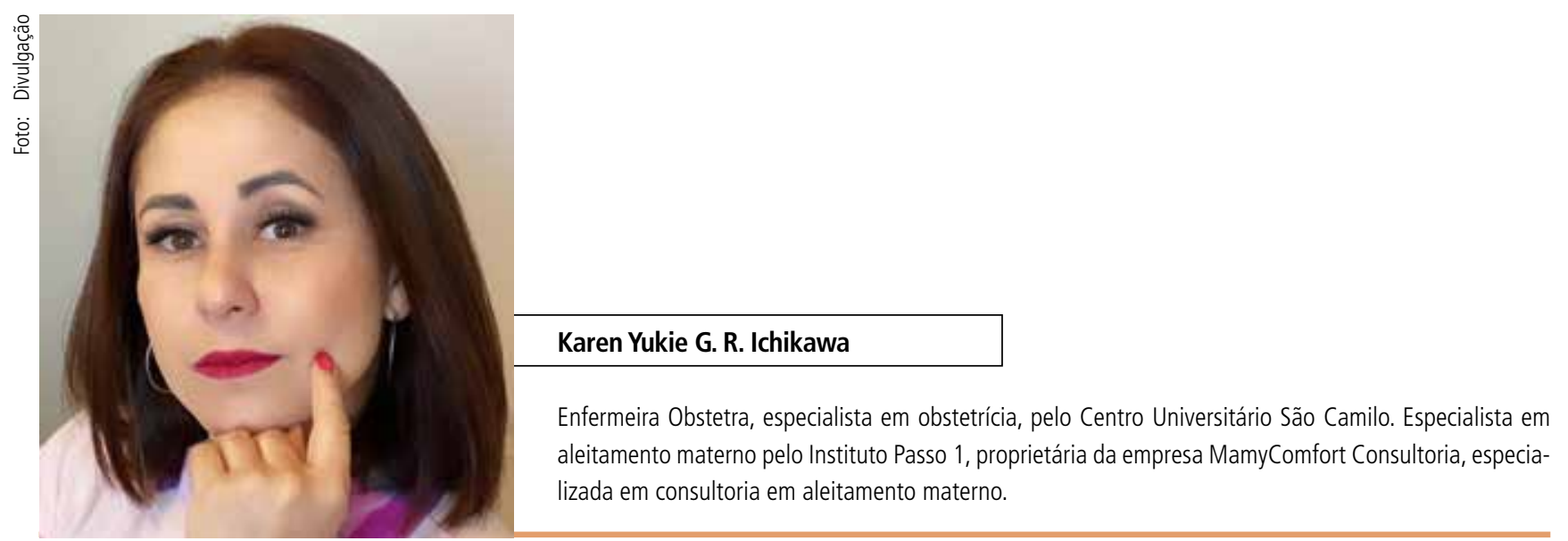

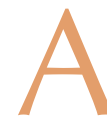
amamentação tem função fundamental no desenvolvimento saudável do ser humano, por isso, é considerada pelo Fundo das Nações Unidas para a Infância (UNICEF) e pela Organização Mundial da Saúde (OMS), além de órgãos de proteção à criança, a ação mais eficiente e eficaz no combate a mortalidade infantil. O leite materno, por ser um alimento completo, constituído por vitamina, proteínas, gordura e carboidratos, além de proteger contra infecções, também melhora o estado nutricional, o desenvolvimento cognitivo e orofacial da criança. É, portanto, a forma mais segura, eficaz e completa de oferecer um crescimento sadio e adequado para a criança.

É papel fundamental da equipe de enfermagem atuar como agentes promotores do aleitamento materno. Os/as enfermeiros/as devem incentivar a amamentação e apoiar as mães para que iniciem a prática do aleitamento materno já na primeira hora de vida do bebê.
Para falar mais sobre aleitamento materno e o papel que a enfermagem deve desempenhar no incentivo a amamentação, conversamos com a Enfermeira Obstetra Karen Yukie G. R. Ichikawa, especialista em obstetrícia e em aleitamento materno.

Revista Nursing: Tratando-se de aleitamento materno, qual é o papel desenvolvido pelo pessoal da enfermagem?

Karen Yukie G. R. Ichikawa: A prática do aleitamento materno está relacionada a fatores de ordem física, psicológica e social, sendo reconhecida a influência dos profissionais de saúde envolvidos neste processo (MARINHO; LEAL, 2004). Sabemos que a partir de 1981, o Brasil passou por mudanças sociais significativas no cenário do aleitamento materno, com o desenvolvimento de uma política estatal, estabelecida pelo Ministério da Saúde. Contudo, mesmo sendo comprovada a importância da amamentação para a criança, nutriz, família e sociedade a luta para incentivar a amamentação e diminuir o desmame precoce ainda é muito grande.

A enfermagem é uma das categorias de saúde que deverá estar capacitada para auxiliar no que diz respeito à amamentação/aleitamento materno. Sendo que o enfermeiro é o profissional que irá identificar e oportunizar momentos para educação, facilitando e estimulando a amamentação, o diagnóstico e o tratamento adequado.

Lembrando que o enfermeiro capacitado em aleitamento materno, poderá atuar junto à população, não somente prestando assistência, mas atuando também na promoção e educação continuada de forma efetiva e duradoura.

Revista Nursing: Qual é a importância do/a enfermeiro/a na assistência às mulheres em relação ao aleitamento materno?

Karen Yukie: O Enfermeiro tem um papel fundamental no aleitamento materno como o de acolher a gestante durante 


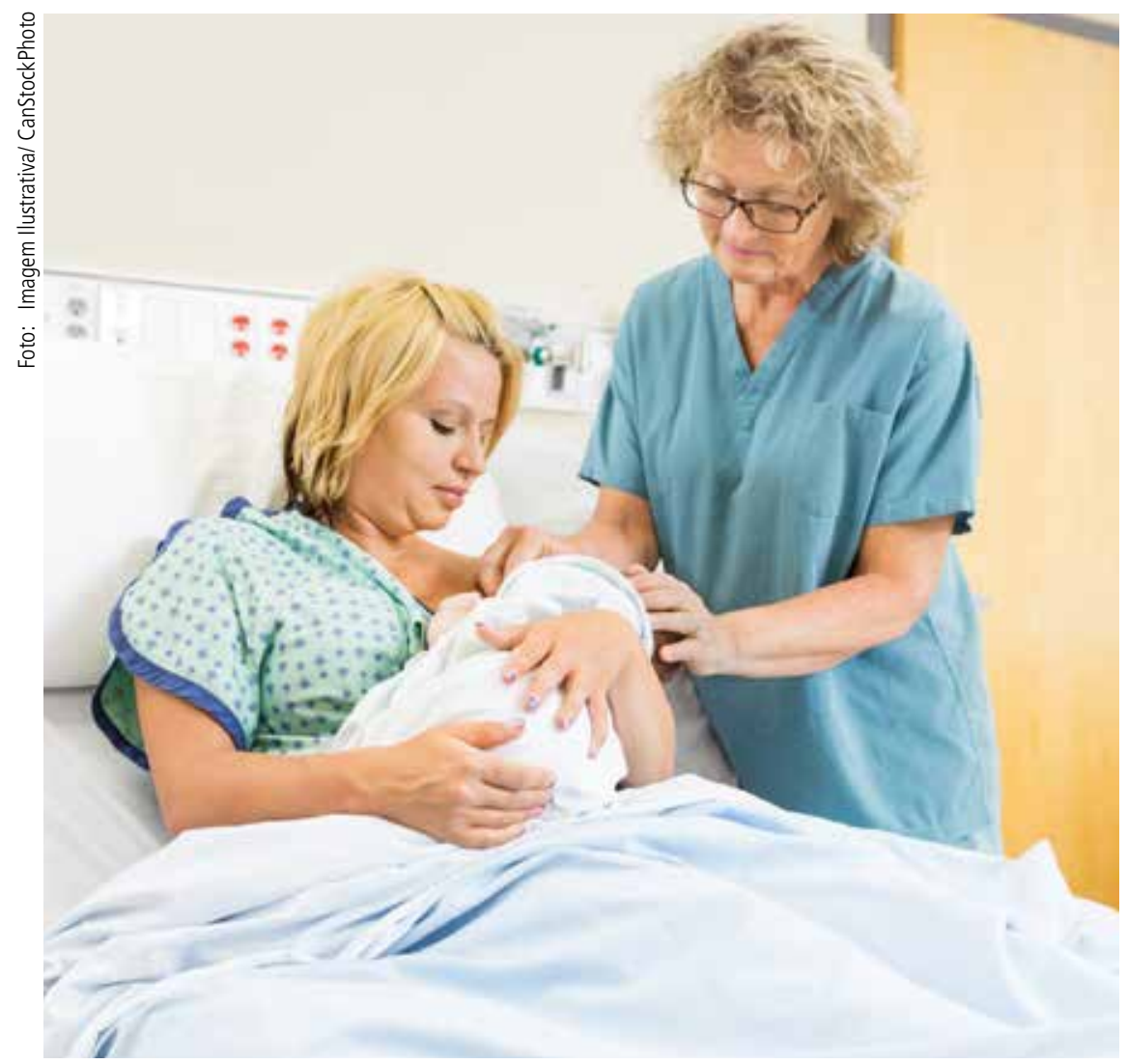

o pré- natal, orientar e tirar suas dúvidas sobre amamentação e apoiar e incentivar a amamentação na primeira hora após o parto, o que reduz consideravelmente a mortalidade neonatal. O enfermeiro saberá aconselhar e ouvir as necessidades dessa nutriz, compreendendo-as e contribuindo para o empoderamento dessa mulher. O trabalho de motivação e empoderamento deverá ser diário e constante para que tenhamos sucesso durante a amamentação. O que contribui para uma amamentação de sucesso é o fortalecimento do binômio mãe e filho e a participação familiar é um forte aliado. Como ponto positivo de um trabalho bem feito e contínuo, além de estimulado, é a redução do desmame precoce. O Ministério da Saúde recomenda a amamentação até os 2 anos de idade, sendo o aleitamento exclusivo nos primeiros 6 meses de vida do bebê, reduzindo as doenças na infância decorrentes do desmame precoce como: diarréia, alergias, doenças respiratórias, obesidade, entre outros. Para as mulheres o ato de amamentar pode reduzir o risco de câncer de mama e de ovário, pois retarda a ovulação e, consequentemente, diminui o nível de hormônios no organismo. O trabalho do enfermeiro produz um impacto positivo na sociedade quando se trata de amamentação/aleitamento materno.

Revista Nursing: Quais práticas devem ser adotadas pelo/a enfermeiro/a, no pré e pós-parto de forma que este/a auxilie a futura mãe sobre os benefícios da amamentação? de tem papel fundamental na promoção, proteção e apoio ao aleitamento materno. Para exercer esse papel ele precisa, além do conhecimento e de habilidades relacionados a aspectos técnicos da lactação, ter um olhar atento e abrangente, sempre levando em consideração os aspectos emocionais, a
Karen Yukie: O profissional da saú- cultura familiar, a rede social de apoio à mulher, entre outros aspectos. As pessoas que assistem as mulheres durante a gravidez e o parto exercem papel fundamental por possibilitar que uma mulher amamente com sucesso. Para tal atividade os profissionais devem rejeitar muitas das práticas históricas nesse campo e ensinar às mulheres apenas aquelas práticas cuja eficácia foi demonstrada. É importante lembrar que o desejo da amamentação não acompanha todas as mulheres, é preciso então que o profissional respeite a decisão de cada mulher, sem pressioná-la ou deixá-la com sentimentos de culpa por não ter amamentado ou não ter conseguido êxito na amamentação. A amamentação é considerada uma estratégia importante de sobrevivência infantil pelo Fundo das Nações Unidas para a Infância (UNICEF), pela Organização Mundial da Saúde (OMS) e por órgãos de proteção à criança. O leite humano protege contra infecções comuns e ainda ajuda na redução da mortalidade infantil, sendo assim, cerca de $13 \%$ a $15 \%$ de todas as mortes de crianças abaixo de cinco anos em todo o mundo, 50\% por doenças respiratórias e $66 \%$ por diarréia, poderiam ser prevenidas com o aleitamento materno. A forma mais segura, eficaz e completa de alcançar o crescimento e desenvolvimento adequados de uma criança é garantindo o aleitamento materno desde a primeira hora de vida extra-uterina. A proteção efetiva que o aleitamento oferece contra otite média, pneumonias e diarréias reduziu as mortes por doenças infecciosas no Brasil. Em relação às doenças crônicas o aleitamento também tem o efeito protetor contra doença de Crohn, linfoma, diabete melito tipo I e alergias. Diante disso, os enfermeiros devem incentivar o aleitamento materno e apoiar as mães para iniciá-lo o mais precocemente, auxiliando-as a adquirir autoconfiança em seu potencial para amamentar o filho. Tendo em vista que a enfermagem presta assistência juntamente a uma equipe 
multidisciplinar que se encontra capacitada para desenvolver a atenção humanizada, torna-se significante o incentivo ao aleitamento materno, com vistas ao melhor desenvolvimento da criança e a promoção do apego entre mãe e bebê.

\section{Revista Nursing: Os profissionais} da enfermagem têm muitas dúvidas sobre aleitamento materno? Quais são as principais?

Karen Yukie: Sim e as dificuldades mais frequentes na enfermagem são:

- Falta de conhecimento e habilidade suficientes, inclusive de comunicação para manejar adequadamente as inúmeras situações que podem servir de obstáculos à amamentação bem sucedida;

- Recomendações inapropriadas;

- Falta de habilidade para dar suporte às mães que estão amamentando;

- Manejo clínico inadequado;

- Estudos realizados em diferentes países têm encontrado com frequência, indiferença, inconsistências e atitudes e conhecimentos inadequados por parte dos profissionais de saúde com relação ao aleitamento materno;

- Falta de habilidade clínica e de aconselhamento em amamentação;

- Falta de treinamento em aconseIhamento em amamentação durante a sua formação acadêmica;

- A existência de crenças e mitos relacionados ao leite materno;

- Falta de conhecimento teórico científico para orientar as nutrizes.

A qualificação destes profissionais deve ser vista como uma prioridade dentre as políticas públicas de saúde, pois será por meio deles que se consolidará o caminho para a construção da valorização da amamentação.
Revista Nursing: Qual é o tipo de curso mais indicado para o profissional que queira se especializar no assunto?

Karen Yukie: O Aleitamento materno é na atualidade uma área de conhecimento interdisciplinar, questão complexa de importância estratégica para a saúde de mulheres e crianças. Envolvendo ações de promoção, prevenção e tratamento clínico, bem como a implementação de iniciativas e políticas públicas específicas.

Para atender essa demanda, algumas instituições estão promovendo cursos de pós-graduação com especialização em aleitamento materno a fim de formar recursos humanos capacitados para atuar no ensino, pesquisa e assistência. O curso de especialização em aleitamento materno já vem acontecendo em São Paulo, com uma gama de profissionais bastante capacitados que estão fazendo a diferença no que se diz respeito ao assunto.

Revista Nursing: Existem profissionais da enfermagem que fazem consultorias focadas em aleitamento materno? Para que servem e como são oferecidas essas consultorias?

Karen Yukie: Sim, existem profissionais da enfermagem que atuam como consultores em aleitamento materno, embora sejam poucos no mercado com essa capacitação para uma população tão grande e necessitada. Esse tipo de consultoria deveria ser estimulada para qualquer público e não somente uma minoria beneficiada. Como enfermeira obstetra e consultora em amamentação sou responsável por um curso que forma consultoras em aleitamento materno, que tem como objetivo capacitar e atualizar profissionais da área de saúde sobre as técnicas, atualizações, evidências, manejo ao aleitamento materno, e aconselhamento para atendimento à dupla mãe-bebê com o objetivo de garantir o sucesso da amamentação, bem como apto a solucionar dificuldades de amamentação entre a dupla. Considero o aperfeiçoamento profissional fundamental. 